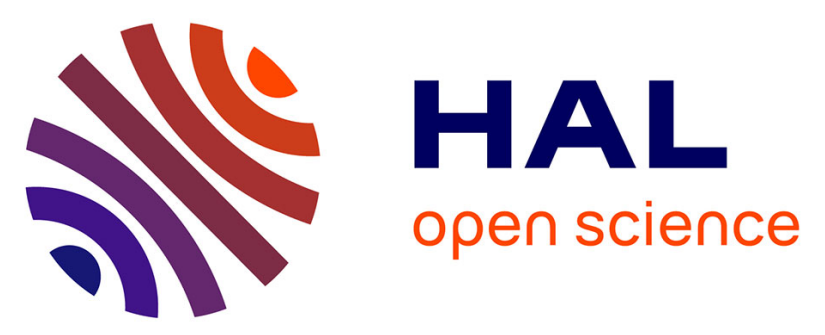

\title{
Evaluation of a new matrix-free laser desorption/ionization method through statistic studies: comparison of the DIAMS (desorption/ionization on self-assembled monolayer surface) method with the MALDI and TGFA-LDI techniques
}

Matthieu Bounichou, Lionel Sanguinet, Kamal Elouarzaki, Olivier Alévêque, Marylène Dias, Eric Levillain, David Rondeau

\section{- To cite this version:}

Matthieu Bounichou, Lionel Sanguinet, Kamal Elouarzaki, Olivier Alévêque, Marylène Dias, et al.. Evaluation of a new matrix-free laser desorption/ionization method through statistic studies: comparison of the DIAMS (desorption/ionization on self-assembled monolayer surface) method with the MALDI and TGFA-LDI techniques. Journal of Mass Spectrometry, 2008, 43 (12), pp.1618 - 1626. 10.1002/jms.1414 . hal-03027828

\section{HAL Id: hal-03027828 \\ https://univ-angers.hal.science/hal-03027828}

Submitted on 27 Nov 2020

HAL is a multi-disciplinary open access archive for the deposit and dissemination of scientific research documents, whether they are published or not. The documents may come from teaching and research institutions in France or abroad, or from public or private research centers.
L'archive ouverte pluridisciplinaire HAL, est destinée au dépôt et à la diffusion de documents scientifiques de niveau recherche, publiés ou non, émanant des établissements d'enseignement et de recherche français ou étrangers, des laboratoires publics ou privés. 


\title{
Evaluation of a new matrix-free laser desorption/ionization method through statistic studies: comparison of the DIAMS (desorption/ionization on self-assembled monolayer surface) method with the MALDI and TGFA-LDI techniques
}

\author{
Matthieu Bounichou, Lionel Sanguinet, Kamal Elouarzaki, Olivier Alévêque, Marylène Dias, \\ Eric Levillain* and David Rondeau*
}

Université d'Angers, CIMA CNRS, UFR Sciences, 2 Bd Lavoisier, 49045 Angers, France

Received 23 January 2008; Accepted 17 March 2008

\begin{abstract}
This work demonstrates that the desorption/ionization on self-assembled monolayer surface (DIAMS) mass spectrometry, a recent matrix-free laser desorption/ionization (LDI) method based on an organic target plate, is as statistically repeatable and reproducible as matrix assisted laser desorption ionization (MALDI) and thin gold film-assisted laser desorption/ionization (TGFA-LDI) mass spectrometries. On lipophilic DIAMS of target plates with a mixture of glycerides, repeatability/reproducibility has been estimated at 15 and $30 \%$ and the relative detection limit has been evaluated at 0.3 and 3 pmol, with and without $\mathrm{NaI}$ respectively. Salicylic acid and its $d_{6}$-isomer analysis confirm the applicability of the DIAMS method in the detection of compounds of low molecular weight. Copyright (C 2008 John Wiley \& Sons, Ltd.
\end{abstract}

KEYWORDS: laser desorption ionization; SAMs; glycerides; mass spectrometry; matrix-free LDI; autoassembled monolayer surfaces

\section{INTRODUCTION}

Rapid analysis of small molecular weight compounds is one of the most widespread applications of mass spectrometry (MS). In this aim, soft ionization methods have been developed to observe gas-phase (pseudo) molecular ions of labile analytes. Among these, the matrix assisted laser desorption ionization (MALDI) has become an outstanding technique in the analysis of a wide variety of compounds. The MALDI method uses a matrix molecule, i.e. a low molecular weight compound absorbing the energy of the laser light pulse. However, the high throughput analyses of low molecular weight molecules $(<1000 \mathrm{~m} / z)$ are relatively difficult to perform in MALDI MS, because the co-crystallization of the matrix and the analyte involves a preparation of the sample before the deposit on the target plate for irradiation. Moreover, the matrix ions interfere with the ions of the analyte in the low $m / z$ range of the MALDI mass spectrum. ${ }^{1}$

In order to avoid these limitations, matrix-free laser desorption/ionization (LDI) methods have been developed

*Correspondence to: Eric Levillain and David Rondeau, Université d'Angers, CIMA CNRS, UFR Sciences, 2 Bd Lavoisier, 49045

Angers, France. E-mail: eric.levillain@univ-angers.fr;

david.rondeau@univ-angers.fr in the last years. To our knowledge, there are few matrixfree LDI methods that really avoid sample preparations and they are usually based on a direct irradiation of the sample deposited on a modified surface. They can be described through two main approaches.

The first one is based on a surface modification by inorganic materials that absorb at specific laser wavelengths. The thin gold film-assisted laser desorption/ionization (TGFALDI) technique proposed by Wahl et al. was related to infrared (IR) $(1064 \mathrm{~nm})$ or visible $(532 \mathrm{~nm})$ beams for LDI of organic samples deposited onto a gold surface. ${ }^{2}$ Other methods such as the desorption/ionization on silicon (DIOS) $)^{3-5}$ and the first developments of the surface assisted laser desorption/ionization (SALDI) ${ }^{6}$ due to Sunner and coworkers were proposed through the study of UV LDI processes. Gold, silicon, and graphite have great potential as photo-absorbing materials and energy transfer mediators for inducing an LDI process. With rapid local heating of the irradiated surface, the presence of a localized electric field leads to a desorption/vaporization step induced by the charge separation on the conductive surface. ${ }^{7}$ This proposed mechanism is in agreement with the observation of cationized molecules in LDI-MS, whereas the formation of a protonated molecule is usually related to gas-phase intermolecular processes that take place in the plume of the laser near the surface, prior 

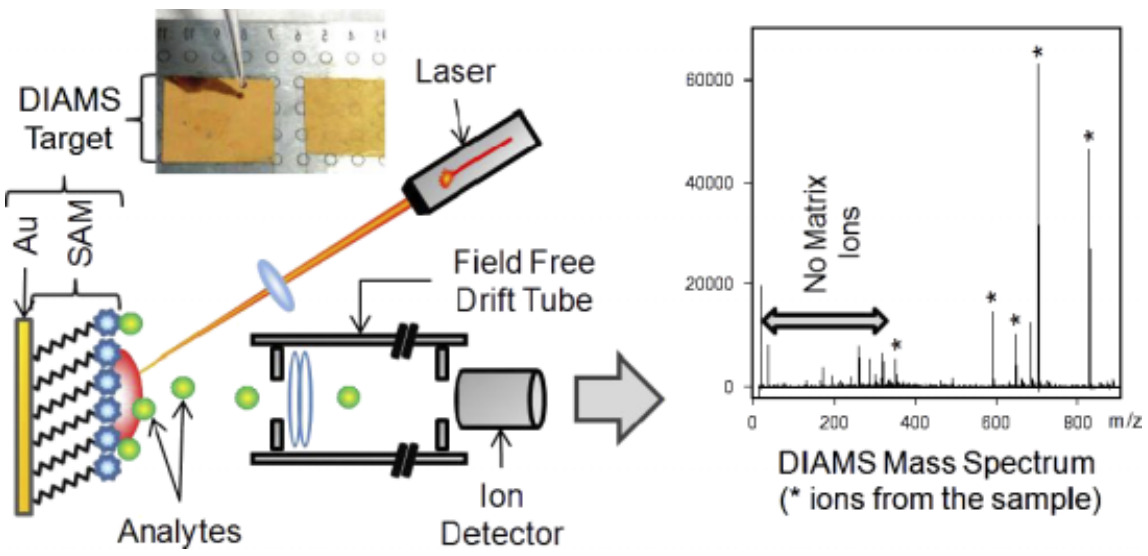

Figure 1. Configuration of desorption/ionization on self-assembled monolayer surface mass spectrometry.

to the ejection of ion toward the mass analyzer. In these matrix-free LDI techniques, the surface quality is particularly relevant. As occurs in photoluminescence of porous silicon, the DIOS process is affected by pore morphology as well as pore size; therefore, the porosity of the silicon is considered as an important parameter for providing an efficient surface in the transfer of energy to the analyte.

The second approach to develop matrix-free LDI uses organic material as a target shooting surface. Hutchens and Yip began to explore this approach with the surface enhanced neat desorption (SEND). ${ }^{8}$ In 2002, Kitagawa et al. continued in this direction and elaborated a polymeric film modified by a terminal function [a cyano-4-hydroxycinnamic acid (HCCA) grafted to a target plate]. ${ }^{9}$ These various surface modifications used in combination with laser desorption MS and their application for the analysis of peptides and proteins have been fully discussed by Afonso et al. ${ }^{10}$

In a previous paper, we have described a new matrix-free LDI method called desorption/ionization on self-assembled monolayer surface (DIAMS) ${ }^{11}$ and have illustrated it in Fig. 1. Its concept is based on the insertion of a covalent bond between the metallic support and the matrix.

In the DIAMS technique, the surface is modified by organic self-assembled monolayers (SAMs) formed by the interaction between a head-group, typically a sulfur atom, and the conductive metallic surface. SAMs are known to be easy to manipulate, very resistant, stable, and not easily reacting. They also provide a very homogeneous hydrophilic or lipophilic surface and some of them even adopt a quasicrystal structure. ${ }^{12}$ In DIAMS analysis, the roles of the monolayer are to absorb at the specific laser wavelength (i.e. $337 \mathrm{~nm}$ ), to maintain the conductivity of the sample metal interface, and to behave as an organized medium that allows the conversion of the laser energy into vaporization and ionization energy.

Consequently, the selected precursor compound of the SAM was an alkane-thiol with a 5,5'-disubstituted-2,2'bithiophene as the chromophore unit (Scheme 1).

The analytical versatility and easy handling of DIAMS were proved with various compounds such as peptides, natural products, and synthetic polymers. Different gasphase ionic species have then been observed in DIAMS-MS, such as protonated, deprotonated, and cationized molecules, whereas no ions due to SAM desorption have been detected.

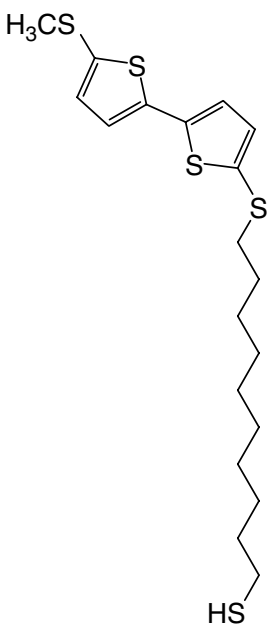

Scheme 1. Molecule 1.

Prior to a full elucidation of the mechanisms involved in the gas-phase ion production in DIAMS-MS, it would be useful to evaluate the analytical potential of the method in terms of sensitivity, reproducibility, and repeatability. The aim is then to compare the strength of the DIAMS method to the MALDI and TGFA-LDI techniques in the same experimental conditions (namely at a similar UV wavelength for the surface irradiation). In this goal, we present a statistical study to evaluate this new analytical tool with standard hydrophobic analytes such as glycerides (Scheme 2). The repeatability/reproducibility and the relative limit of detection of each analysis method are estimated using the glyceride mixture. Note that for the statistic study a sampling of 40 DIAMS target plates has been prepared in the same conditions, with the analysis of 12 spots by plate. For the analysis of low molecular weight compounds in DIAMS/MS, the statistical study was applied to the detection of salicylic acid $(\mathrm{Mw}=138)$.

\section{EXPERIMENTAL SECTION}

\section{Chemicals}

Standard compounds such as the $\alpha$-mono-cis-9-hexa decanoin $\left(\mathrm{G} 1, \mathrm{Mw}=328.49 \mathrm{~g} \mathrm{~mol}^{-1}\right)$, the $\alpha, \alpha^{\prime}$-dihexa decanoin $\left(\mathrm{G} 2, \mathrm{Mw}=568.93 \mathrm{~g} \mathrm{~mol}^{-1}\right)$, the $\alpha, \alpha^{\prime}$-dioctade canoin $\left(\mathrm{G} 3, \mathrm{Mw}=625.02 \mathrm{~g} \mathrm{~mol}^{-1}\right)$, the tritridecanoin (G4, 
<smiles>CC/C=C/[CH]C(=O)OCC(O)CO</smiles>

G1

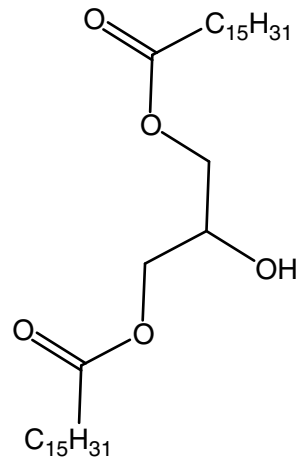

G2

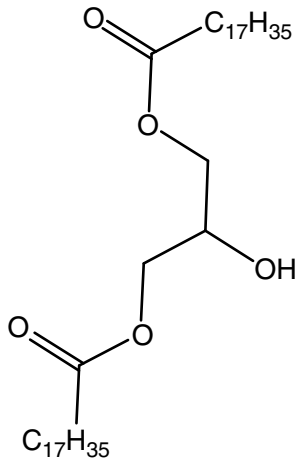

G3

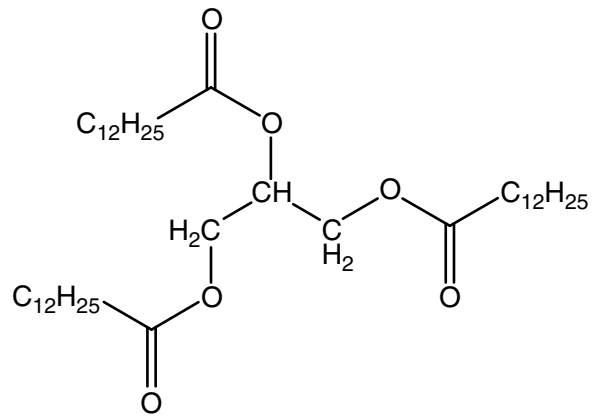

G4

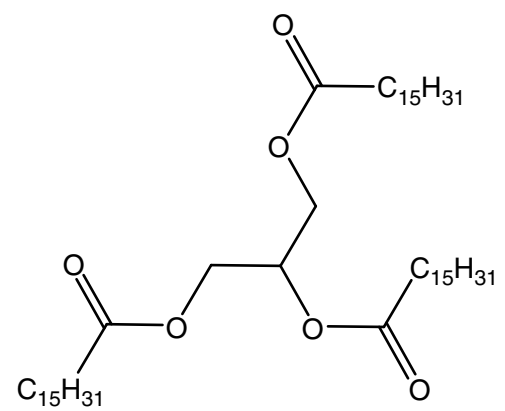

G5

Scheme 2. Structure of analyzed glycerides. Note that G1 is the $\alpha$-mono-cis-9-hexadecanoin; G2 is the $\alpha, \alpha^{\prime}$-dihexadecanoin; G3 is the $\alpha, \alpha^{\prime}$-dioctadecanoin; $\mathbf{G} 4$ is the tritridecanoin; and $\mathbf{G 5}$ is the trihexadecanoin.

$\left.\mathrm{Mw}=681.08 \mathrm{~g} \mathrm{~mol}^{-1}\right)$, and the trihexadecanoin (G5, Mw $=$ $807.32 \mathrm{~g} \mathrm{~mol}^{-1}$ ) were purchased from Sigma-Aldrich (Saint Quentin Fallavier, France) and stored at $-20^{\circ} \mathrm{C}$. Salicylic acid was purchased from Prolabo (Fontenay sous Bois, France). Salicylic acid- $d_{6}$ was obtained from Sigma-Aldrich (Saint Quentin Fallavier, France). The 2,5-dihydroxybenzoic acid (DHB) matrix was purchased from Sigma-Aldrich (Saint Quentin Fallavier, France). Sodium iodide was obtained from Acros Organics. Methylene chloride (HPLC grade) and methanol were obtained from sodium dodecyl sulfate (SDS). The cyanoacrylate used was the superglue3 purchased from Henkel France SA (Boulogne Billancourt, France). The conductive- $C$ cement was obtained from Neubauer Chemikalien (Munster, Germany).

\section{Elaboration of TGFA and DIAMS plates}

The support was elaborated from 'brand new' substrates prepared by deposit of successive layers of chrome $(5 \mathrm{~nm})$ and then gold $(35 \mathrm{~nm})$ on borosilicate glass $(20 \times 20 \mathrm{~mm})$ by physical vapor deposition (PVD). These substrates were either directly used for TGFA-LDI or immersed for 2 days under controlled atmosphere [dry, oxygen-free $(<1 \mathrm{ppm})$ argon] in a solution of thiol molecules in methylene chloride (typically $1 \mathrm{~mm}$ ) for the elaboration of the SAMs before the DIAMS application.

\section{Electrochemistry}

Electrochemical experiments were carried out with an EGG PAR 273A potentiostat with positive feedback compensation in a glove box containing dry, oxygen-free ( $<1 \mathrm{ppm})$ argon, at room temperature. Cyclic voltammetry $(\mathrm{CV})$ was performed in a three-electrode cell equipped with a platinum-plate counter electrode and a silver wire served as the quasireference electrode; its potential was checked against the ferrocene/ferricinium couple $\left(\mathrm{Fc} / \mathrm{Fc}^{+}\right)$before and after each experiment. In both cases, the potentials were then recalculated against $\mathrm{Fc} / \mathrm{Fc}^{+} . \mathrm{CVs}$ were recorded in dry HPLC-grade methylene chloride with tetrabutylammonium hexafluorophosphate $\left(\mathrm{Bu}_{4} \mathrm{NPF}_{6}\right)$ as the supporting electrolyte. Based on repetitive measurements, absolute errors on potentials were found to be $\sim 5 \mathrm{mV}$.

\section{Modification of the MALDI target}

The TGFA or DIAMS plates $(20 \times 20 \mathrm{~mm}$ substrate modified or not by the monolayer) were thoroughly washed with clean methylene chloride and then stuck on a classic MALDI target (Bruker Scout 384) with cyanolite glue. The electrical contact between the gold or organic-modified surface and the metal surface of the Scout 384 was guaranteed by a conductive cement. 


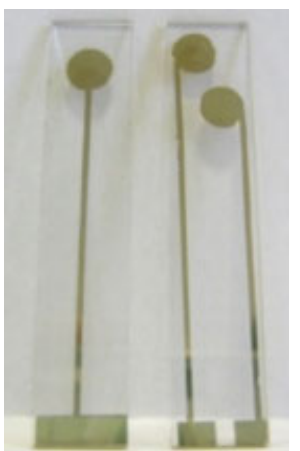

(A)

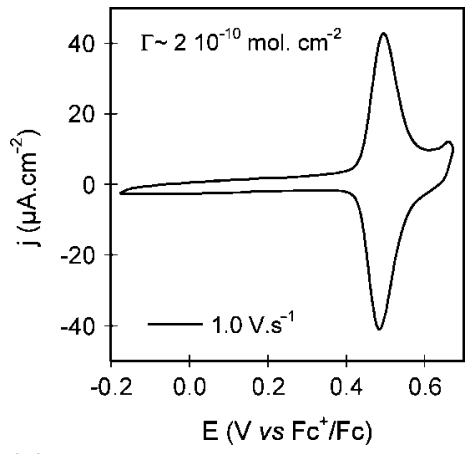

(B)

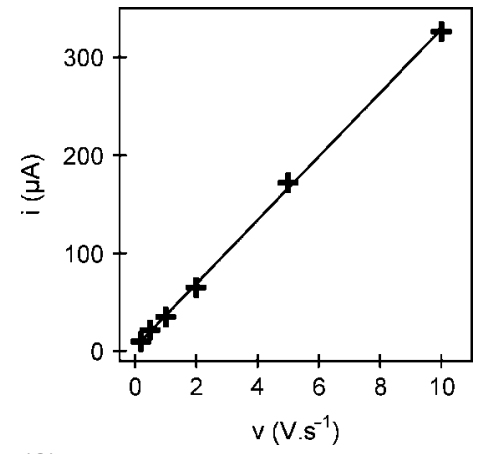

(C)

Figure 2. (A) Picture of the gold substrates prepared with PVD to electrochemically characterize the monolayers. (B) Cyclic voltammogram of one monolayer obtained in $\mathrm{CH}_{2} \mathrm{Cl}_{2}$ with $\mathrm{Bu}_{4} \mathrm{NPF}_{6}(0.1 \mathrm{M})$. (C) Variation of the intensity of the oxidation peak with scan rate.

\section{Sample preparation and deposit}

A standard solution containing the compounds G1-G5 was prepared in order to achieve a final concentration of $0.2 \mathrm{mg} / \mathrm{ml}$ per glyceride in a mixture of chloroform/methanol $(2: 1, \mathrm{v} / \mathrm{v})$. A diluted solution in the same solvent mixture was also prepared from the standard solution such that the ratio of solvent to standard solution was 9:1 (v/v). In MALDI analyses, the standard solution was mixed with a solution of DHB $(20 \mathrm{mg} / \mathrm{ml})$ in a $1: 1(\mathrm{v} / \mathrm{v})$ ratio prior to the deposition onto the target. When required, sodium iodide was added by mixing the standard solution with a NaI solution $(10 \mathrm{mg} / \mathrm{ml})$ in a ratio 10:1 (v/v). The salicylic acid standard solutions were prepared in methanol. All deposits were carried out by dry droplet method $(0.5 \mu \mathrm{l}$ was spotted for LDI and DIAMS experiments, and $1 \mu \mathrm{l}$ was spotted for MALDI).

\section{Mass spectrometry}

MS analyses were performed on a Bruker Biflex III timeof-flight (TOF) mass spectrometer (Bruker-Daltonic, Bremen Germany), equipped with a Scout 384 probe ion source and a 337-nm pulsed nitrogen laser (model VSL-337i, Laser Science Inc., Boston, MA) having a repetition rate of $5 \mathrm{~Hz}$ and a pulse width of 2 ns. Mass spectra were obtained in positive reflector mode using Flex control software (version Bruker-Daltonic, Bremen Germany). The ions were accelerated with a $19-\mathrm{kV}$ acceleration voltage, a 200-ns delayed extraction, and a 15.4$\mathrm{kV}$ potential difference between the target and the extraction lens. The voltage of the reflectron was set at $20 \mathrm{kV}$. In all MS analyses, no matrix ion suppression pulse was used.

\section{Laser}

Calibrated with a power meter, the energy pulse of $\mathrm{N}_{2}$ Laser was optimized in order to obtain the best signal-to-noise ratio for all the ions characteristic of the analyzed species and to minimize the presence of low $\mathrm{m} / \mathrm{z}$ ions that could result in the fragmentation of the detected parent ions. This laser energy was $\sim 3 \mu \mathrm{J} /$ pulse (i.e. $70 \%$ of laser attenuation) in DIAMS and $\sim 9 \mu \mathrm{J} /$ pulse (i.e. $40 \%$ of laser attenuation) in MALDI and TGFA-LDI.

\section{Automatic acquisition (AutoXecute method)}

Mass spectra were recorded using an automated data acquisition protocol, AutoXecute (Bruker Daltonics). Spectra were selected according to their resolution and signal-tonoise ratio. Fuzzy control parameters of AutoXecute were as follows: Filter Size parameter was set to 1; the Judgment Window was $m / z 680-720$; the smoothing and the base line subtraction were activated and only spectra with a resolution higher than 500 and a signal-to-noise ratio higher than 2 were recorded. In order to compare the different results obtained, this setup should not be modified because the spectra and statistical variance of the intensity are strongly dependent on these parameters.

\section{Data processing}

Baseline of mass spectra was set to zero and the intensities were normalized. The normalization consists of first recording the intensities of the significant peaks, subsequently dividing the whole mass spectrum by the sum of significant peaks intensities and, finally multiplying it by 100 .

\section{RESULTS AND DISCUSSION}

\section{Evaluation of SAMs by CV}

The DIAMS plates used in this study are covered with monolayers elaborated from molecule 1 (Scheme 1) on a fresh gold substrate. The selection of a bithiophene moiety as the chromophore unit was driven either for its high molar extinction coefficient at $337 \mathrm{~nm}\left(\mathrm{ca} 20000 \mathrm{~L} \mathrm{~mol}^{-1} \mathrm{~cm}^{-1}\right)$ or for its electrochemical behavior, the first oxidation of this bithiophene unit being completely reversible with a halfwave potential $E_{1 / 2}=+0.49 \mathrm{~V}$ versus $\mathrm{Fc} / \mathrm{Fc}^{+} .{ }^{13}$ This second property allows the characterization of the monolayers by $\mathrm{CV}$ in order to evaluate the stability, organization, and surface coverage. $^{12}$

Figure 2 clearly shows that all the analytical criteria for a 'good' monolayer were satisfied:

- The proportionality between the intensity peaks and the scan rate, which confirms that the molecule is immobilized on the substrate;

- A unique potential for reduction and oxidation peaks, which indicates a well-organized monolayer, as well as the presence of only one redox species; 


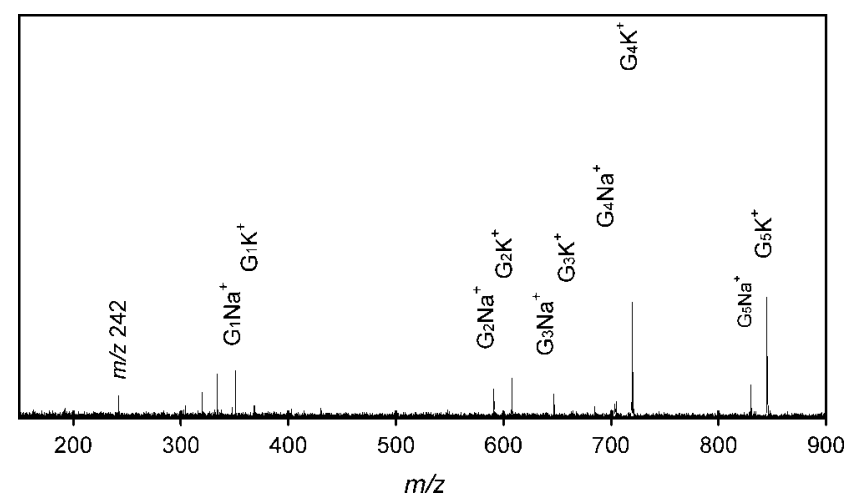

Figure 3. DIAMS mass spectrum of the five analyzed glycerides showing the $[\mathrm{M}+\mathrm{Na}]^{+}$and $[\mathrm{M}+\mathrm{K}]^{+}$ions detected for the compounds $\mathrm{G} 1$ ( $\mathrm{m} / \mathrm{z} 351$ and 367), G2 ( $\mathrm{m} / \mathrm{z} 591$ and 607), G3 ( $\mathrm{m} / \mathrm{z} 647$ and 663), G4 ( $\mathrm{m} / \mathrm{z} 703$ and 719$)$, and G5 ( $\mathrm{m} / \mathrm{z}$ 829 and 845) (see Experimental Section for the signification of the notation G1, G2, G3, G4, and G5 of the glycerides). Note the presence of the tetrabutylammonium ion $(\mathrm{m} / \mathrm{z} 242)$ in the mass spectra due to a contamination of the plates.

- A large surface coverage $\left(\Gamma=2( \pm 0.4) 10^{-10} \mathrm{~mol} \mathrm{~cm}^{-2}\right)$;

- The electrochemical stability of SAMs, tested by cycling at $10 \mathrm{mV} \mathrm{s}^{-1}$, observed over several weeks.

Based on our experience, such an electrochemical characterization is an important step. Indeed, a SAM that does not present the electrochemical behavior previously described, appears to be related to a degradation process under laser irradiation. We estimate the percentage of imperfect materials as being lower than $5 \%$.

\section{Stability of SAMs versus laser energy}

The glyceride G1 (Scheme 2) was chosen as the standard analyte for testing the resistance of bithiophenic SAMs to laser irradiation. With a laser attenuation greater than $70 \%(\sim 3 \mu \mathrm{J} /$ pulse), no mass spectrum could be recorded. Above $70 \%$ laser attenuation, the ions due to the desorption/ionization process of the analyte are observed, typically $[\mathrm{M}+\mathrm{Na}]^{+}\left(m / z\right.$ 703) and $[\mathrm{M}+\mathrm{K}]^{+}(m / z$ 719). At higher laser energies, the ions characteristic of the plate degradation are detected. For the lowest laser attenuation laser (30\% laser attenuation $-\sim 12 \mu \mathrm{J} /$ pulse), gold clusters appear in the mass spectrum, i.e. ions at $m / z 197,394$, and 591). Note that from a laser attenuation value of $55 \%$ (energy beam close to $5 \mu \mathrm{J} /$ pulse), ions at $\mathrm{m} / \mathrm{z} 398$ and 414 are observed, but their structure is not yet fully established. On the one hand, the aim of the present article is not to characterize SAMs using LDI/MS analyses. On the other, the effect of the laser fluence on the stability of organothiol SAMs on gold surfaces has been previously reported in literature. ${ }^{14,15} \mathrm{Nev}$ ertheless, statistic studies were performed at $\sim 3 \mu \mathrm{J} /$ pulse laser energy, since at this value the monolayers elaborated for the present study allow observation of only the analyte ions in the DIAMS mass spectrum. In MALDI and TGFA-LDI methods, laser energy was adjusted to optimize the setup and to observe the ions from glycerides. It has been set to $40 \%$ ( $\sim 9 \mu \mathrm{J} /$ pulse). Note that the results obtained in TGFA-LDI under a $70 \%$ attenuation laser are similar to those obtained at $30 \%$.

\section{Methods}

To evaluate the DIAMS method, the following experimental conditions were fixed:

1. A sampling of 40 DIAMS target plates (12 spots per plate) prepared in the same conditions and previously tested through $\mathrm{CV}$;

2. An automated data acquisition procedure to record mass spectra, developed to minimize systematic errors (see Experimental Section);

3. A data processing to normalize mass spectra (see Experimental Section);

4. A standard solution of the glycerides G1, G2, G3, G4, and G5 (see Experimental Section) was directly spotted into the DIAMS plate. Note that such standard compounds are considered as well adapted to lipophilic plates and are known through their reactivity in MALDI/TOF MS. ${ }^{16-20}$

The results of DIAMS-MS analysis of the glyceride mixture are reported in the Fig. 3. The mass spectrum of Fig. 3 exhibits the sodium and potassium adducts of the five analyzed glycerides, i.e. ten significant peaks in a mass-tocharge ratio range encompassing the $m / z 351$ and 845 ions.

Numerous studies have reported the use of a cationic agent (i.e. sodium iodide) to increase the detection sensitivity in the glyceride analysis, namely in MALDI-TOF ${ }^{18,19}$ or LDI, $^{21}$ by adducts formation $\left([\mathrm{M}+\mathrm{Na}]^{+},[\mathrm{M}+\mathrm{K}]^{+}\right)$. In our case, the DIAMS method was evaluated in conditions that we have noted as hard (i.e. without NaI) and soft (i.e. with $\mathrm{NaI}$ ) and the results were then compared with TGFA-LDI and MALDI methods, using the same experimental conditions. Figure 4 displays DIAMS, MALDI, and TGFA-LDI mass spectra obtained with the same standard solution in automatic mode (1000 accumulations), with and without $\mathrm{NaI}$.

Figure 4 confirms that no signal is detected in the low $\mathrm{m} / \mathrm{z}$ range of mass spectra obtained with DIAMS method, whereas the MALDI and TGFA-LDI mass spectra exhibit a relatively intense background below $m / z 400$. At this stage, it must be mentioned that in MALDI MS, the numerous peaks observed below 400 Th are often assigned to matrix ions, ${ }^{22}$ but the numerous signals observed in low $\mathrm{m} / \mathrm{z}$ range can also be attributed to pyrolysis processes of the analytes before the ejection in the gas phase. From the mass spectra of Fig. 4, it appears that while the G4 and G5 species are greatly favored with regards to the G2 and G3 species in DIAMS, all the corresponding peaks are of similar intensity in MALDI and TGALDI. Also, in contrast to the MALDI mass spectra, $[\mathrm{M}+\mathrm{K}]^{+}$ ions are observed as the most abundant ionic species for the glycerides G2 to G5 in DIAMS and TGA-LDI analyses without $\mathrm{NaI}$. The observation of intense $[\mathrm{M}+\mathrm{K}]^{+}$ions even without the addition of cationizing agent has been previously mentioned in TGA-LDI and could be attributed to a thermal desorption process of cationized molecule due to the rapid heating of the surface. ${ }^{2}$ Such a mechanism could be suggested as a first approximation to the DIAMS case. However, it could also be interesting to envisage specific interactions with the modified surface that should influence the desorption process yield. Furthermore, while the presence of $\mathrm{NaI}$ leads to the observation of DIAMS and MALDI mass spectra free of $[\mathrm{M}+\mathrm{K}]^{+}$ions, these ions are already present in TGA-LDI 

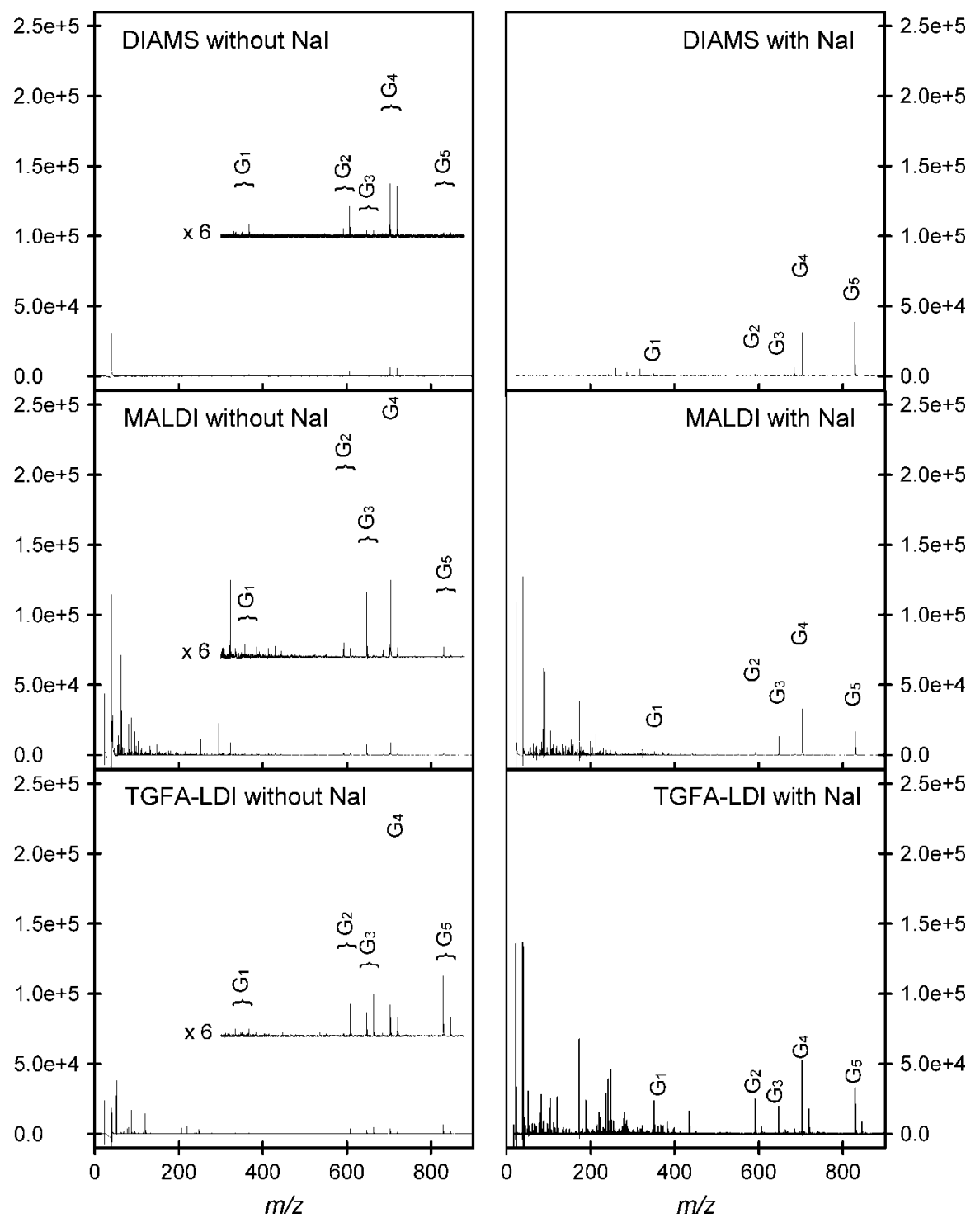

Figure 4. Mass spectra performed in automatic mode (1000 accumulations) by DIAMS, MALDI, and TGFA-LDI methods with and without Nal used as cationizing agent.

suggesting here that the two matrix-free LDI methods can be described by two different desorption/ionization process in this case. Finally, the behavior of the desorbed species in the plume of the laser pulse and their reactivity in the gas phase should also be taken into account in MALDI and in the above two methods. Since different desorption and ionization processes can be involved in the three desorption/ionization methods tested, the intensity of each peak detected in the mass spectra of one method cannot be compared to another. Furthermore, if the significant peaks of a glycerides mixture are observed and identified with all tested ionization methods, it must be noted that the peaks of the sodium and potassium adducts $(m / z 351$ and 367$)$ of the glyceride $\mathrm{G} 1$, were not taken into account in the repeatability and reproducibility studies. Indeed, in MALDI and TGFA-LDI analysis, they are located in an $m / z$ range containing some parasite ions.

The addition of sodium iodide in the sample mixture led to an enhancement of the peak intensities and an increase of the sensitivity of DIAMS, MALDI, and TGFA-LDI methods. However, the use of this cationic agent implied that the glycerides were ionized essentially as sodium adducts; therefore the peaks corresponding to $[\mathrm{M}+\mathrm{K}]^{+}$disappeared.

\section{Repeatability}

The study of repeatability led to an estimation of the percentage standard deviation of the intensities of each significant peak during a series of repetitive measurements, performed on 12 spots in DIAMS, TGFA-LDI, and MALDI conditions.

Table 1 gathers the mean values and standard deviations of each significant peak, obtained from the mass spectra of G2, G3, G4, and G5 in DIAMS, TGFA-LDI, and MALDI conditions without $\mathrm{NaI}$.

For a given significant peak, the mean values are not comparable from one method to another because each of them involves different desorption and ionization processes. For a given LDI method, the percentage standard deviations range from 10 to $40 \%$, thus in agreement with previous studies on quantitative analysis in MALDI $^{23}$ and DIOS. ${ }^{24}$ 
Table 1. Mean values and standard deviations calculated from mass spectral data of four glycerides $\left[\alpha, \alpha^{\prime}\right.$-dihexadecanoin(G2, $\left.\mathrm{Mw}=568.93 \mathrm{~g} \mathrm{~mol}^{-1}\right) ; \alpha, \alpha^{\prime}$-dioctadecanoin(G3, Mw = $\left.625.02 \mathrm{~g} \mathrm{~mol}^{-1}\right)$; tritridecanoin $\left(\mathrm{G} 4, \mathrm{Mw}=681.08 \mathrm{~g} \mathrm{~mol}^{-1}\right)$; and trihexadecanoin (G5, Mw $\left.=807.32 \mathrm{~g} \mathrm{~mol}^{-1}\right)$ ] without $\mathrm{Nal}$

\begin{tabular}{|c|c|c|c|c|c|c|c|c|c|}
\hline & $m / z$ & 591 & 607 & 647 & 663 & 703 & 719 & 829 & 845 \\
\hline \multirow[t]{3}{*}{ DIAMS } & Mean & 10 & 1.9 & 7 & 0.9 & 39 & 16 & 20 & 6 \\
\hline & Standard deviation & 3 & 0.8 & 2 & 0.3 & 4 & 6 & 4 & 2 \\
\hline & Percentage standard deviation (\%) & 26 & 44 & 24 & 34 & 11 & 38 & 20 & 37 \\
\hline \multirow[t]{3}{*}{ MALDI } & Mean & 17 & 5 & 12 & 3 & 30 & 13 & 16 & 4 \\
\hline & Standard deviation & 3 & 2 & 2 & 1 & 5 & 5 & 2 & 2 \\
\hline & Percentage standard deviation (\%) & 16 & 36 & 13 & 42 & 17 & 38 & 12 & 39 \\
\hline \multirow[t]{3}{*}{ TGFA-LDI } & Mean & 13 & 6 & 8 & 3 & 33 & 18 & 14 & 6 \\
\hline & Standard deviation & 2 & 2 & 1 & 0.9 & 6 & 4 & 2 & 2 \\
\hline & Percentage standard deviation (\%) & 16 & 36 & 12 & 33 & 19 & 22 & 17 & 29 \\
\hline
\end{tabular}

The addition of sodium iodide in the sample mixture led to analogous results. Nevertheless, the enhancement of the peak intensities induced a decrease in all the percentage standard deviations of DIAMS, MALDI, and TGFA-LDI methods (Table 2).

These results reveal that the DIAMS method is as statistically repeatable as the MALDI and TGFA-LDI ones.

\section{Reproducibility}

The reproducibility study led to an estimation of the percentage standard deviation of the intensities of each significant peak during a series of repetitive measurements performed on four different DIAMS target plates, all developed in the same experimental conditions. The results obtained clearly showed that the relative intensity mean value and standard deviation were very similar from one plate to another (Fig. 5). However, this was not sufficient to conclude that the DIAMS method is reproducible.

One-way analysis of variance (ANOVA) (i.e. $F$ test statistic) was performed to confirm the reproducibility of the DIAMS method (Table 3). The assumptions were as follows:

- The samples gave populations, which were normally or approximately normally distributed;

- The samples were independent;

- The variances of the populations were equal.

The null hypothesis was that all population mean values were equal; the alternative hypothesis was that at least one mean was different.

Table 2. Percentage standard deviation of DIAMS, MALDI, and TGFA-LDI methods obtained from mass spectra of four glycerides $\left[\alpha, \alpha^{\prime}\right.$-dihexadecanoin(G2, Mw $=568.93 \mathrm{~g} \mathrm{~mol}^{-1}$ ); $\alpha, \alpha^{\prime}$-dioctadecanoin(G3, $\mathrm{Mw}=625.02 \mathrm{~g} \mathrm{~mol}^{-1}$ ); tritridecanoin (G4, Mw = $681.08 \mathrm{~g} \mathrm{~mol}^{-1}$ ); and trihexadecanoin (G5, $\left.\left.\mathrm{Mw}=807.32 \mathrm{~g} \mathrm{~mol}^{-1}\right)\right]$ with and without Nal

\begin{tabular}{lcc}
\hline Method & $\begin{array}{c}\text { Percentage standard } \\
\text { deviation without NaI (\%) }\end{array}$ & $\begin{array}{c}\text { Percentage standard } \\
\text { deviation with NaI (\%) }\end{array}$ \\
\hline DIAMS & 29 & 13 \\
MALDI & 27 & 12 \\
TGFA-LDI & 23 & 13 \\
\hline
\end{tabular}

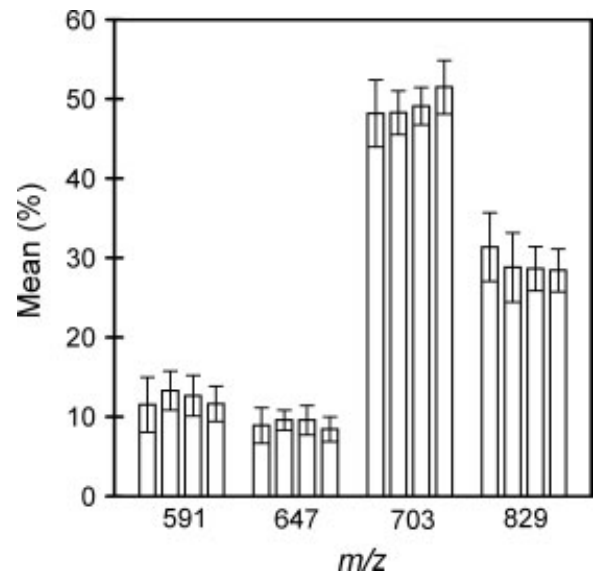

Figure 5. A comparison of mean values and standard deviations of four DIAMS target plates calculated from the mass spectral data of four glycerides $\left[\alpha, \alpha^{\prime}\right.$-dihexadecanoin (G2, $\mathrm{MNa}^{+}: \mathrm{m} / \mathrm{z}$ 591); $\alpha, \alpha^{\prime}$-dioctadecanoin (G3, $\mathrm{MNa}^{+}: \mathrm{m} / \mathrm{z}$ 647); tritridecanoin (G4, $\mathrm{MNa}^{+}: \mathrm{m} / \mathrm{z} 703$ ); and trihexadecanoin $\left(\mathrm{G} 5, \mathrm{MNa}^{+}: \mathrm{m} / \mathrm{z}\right.$ 829)] with Nal.

For 48 spots spread out on four different DIAMS target plates, the calculated Fisher values $F$ from Table 3 for the following peaks: $m / z 591,647,703$, and 829 were $1.19,1.19$, 2.67 , and 1.74, respectively. As all these values were lower than the tabulated Fisher statistic critical value $F_{\text {crit }}=2.82$ (for a numerator of freedom degrees of 3, a denominator of freedom degrees of 44 , and a $95 \%$ confidence level), our conclusion was to accept the null hypothesis.

The ANOVA test was then generalized on all the 40 DIAMS target plates and the $F$ test statistic confirmed that the DIAMS method was a reproducible method with a $95 \%$ confidence level.

\section{Relative detection limit}

The relative detection limit was defined as the lower quantity of analyte deposited to produce a signal threefold greater than the noise intensity. ${ }^{25}$ In our case, this relative detection limit was determined using a mixture of glycerides at various concentrations from $2 \times 10^{-2}$ to $2 \times 10^{-4} \mathrm{~g} \mathrm{l}^{-1}$, with or without NaI. Figure 6 shows the results obtained for the analysis of a mixture of glycerides at different concentrations with the DIAMS method. To carry out these 
Table 3. One-way analysis of variance on $\mathrm{m} / \mathrm{z} 703$

\begin{tabular}{|c|c|c|c|c|}
\hline Spot & Plate 1 & Plate 2 & Plate 3 & Plate 4 \\
\hline 1 & 49.67 & 45.44 & 53.53 & 56.08 \\
\hline 2 & 46.20 & 48.35 & 44.06 & 50.37 \\
\hline 3 & 47.26 & 46.25 & 50.06 & 53.92 \\
\hline 4 & 56.85 & 52.35 & 48.83 & 55.97 \\
\hline 5 & 45.26 & 46.62 & 47.99 & 50.18 \\
\hline 6 & 43.41 & 47.23 & 50.20 & 48.00 \\
\hline 7 & 46.80 & 45.56 & 50.55 & 51.28 \\
\hline 8 & 43.74 & 52.42 & 51.26 & 50.81 \\
\hline 9 & 47.06 & 44.89 & 48.62 & 55.38 \\
\hline 10 & 52.20 & 50.01 & 48.28 & 46.66 \\
\hline 11 & 45.55 & 48.84 & 48.81 & 52.22 \\
\hline 12 & 54.12 & 51.54 & 46.94 & 46.75 \\
\hline Total & 578.12 & 579.50 & 589.13 & 617.62 \\
\hline Mean & 48.18 & 48.29 & 49.09 & 51.47 \\
\hline Standard deviation & 4.21 & 2.74 & 2.35 & 3.36 \\
\hline \multirow{2}{*}{$\begin{array}{c}\text { Percentage standard } \\
\text { deviation }(\%)\end{array}$} & 9 & 6 & 5 & 7 \\
\hline & $\begin{array}{l}\text { Degrees of } \\
\text { freedom }\end{array}$ & \multicolumn{2}{|c|}{$\begin{array}{l}\text { Sum of } \\
\text { squares }\end{array}$} & $\begin{array}{l}\text { Mean } \\
\text { square }\end{array}$ \\
\hline Regression & 3 & \multicolumn{2}{|c|}{84.19} & 28.06 \\
\hline Residual & 44 & \multicolumn{2}{|c|}{462.28} & 10.51 \\
\hline \multirow[t]{2}{*}{ Total } & 47 & \multicolumn{2}{|c|}{546.47} & \\
\hline & & \multicolumn{2}{|c|}{ Fstatistic } & 2.67 \\
\hline
\end{tabular}

measurements, $0.5 \mu \mathrm{l}$ of the different mixtures were spotted onto a DIAMS target. As shown in Fig. 6, all glycerides have been detected up to 3 pmol without $\mathrm{NaI}$ and up to 0.3 pmol when NaI was added to the mixture. A similar experiment was performed with classical MALDI method: different solutions of a glyceride mix were introduced in a DHB solution and $1 \mu \mathrm{l}$ was spotted on the MALDI target. In this case, the relative detection limit for all four glycerides was restricted to $15 \mathrm{pmol}$ without $\mathrm{NaI}$ and to 1.5 pmol with NaI. In conclusion, the substitution of classical MALDI by DIAMS improved the relative detection limit by a factor of 5 .

\section{DIAMS/MS of salicylic acid}

With regard to the applicability of the matrix-free LDI methods in the analyses of low molecular compounds whose ions could interfere with the matrix ions in MALDI, the present study is applied to the detection of salicylic acid in DIAMS. Note that this compound was previously analyzed in DIOS MS using the negative ion mode. ${ }^{26}$ For the DIAMS/MS study, we have chosen the positive ion mode for the glyceride analysis. The DIAMS mass spectrum of salicylic acid and of its $d_{6}$ isomer exhibits intense signals at $m / z 139$ and 143 corresponding to the quasi-molecular ions $\left[\mathrm{HO}-\mathrm{C}_{6} \mathrm{H}_{4}-\mathrm{CO}_{2} \mathrm{H}+\right.$ $\mathrm{H}]^{+}$and $\left[\mathrm{HO}-\mathrm{C}_{6} \mathrm{D}_{4}-\mathrm{CO}_{2} \mathrm{H}+\mathrm{H}\right]^{+}$, respectively (Fig. 7). No interfering signals are detected in this low $m / z$ range. The $14 \%$ percentage standard deviation of the DIAMS analysis was obtained from four repeated measurements. A 0.5-nmol relative detection limit was determined by three DIAMS

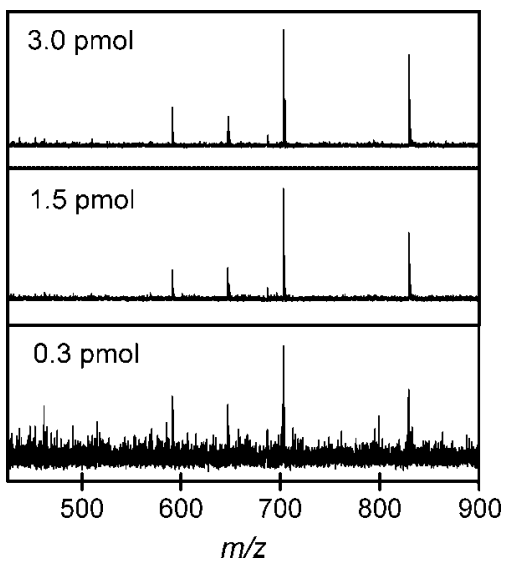

Figure 6. Relative detection limit of a mixture of four glycerides $\left[\alpha, \alpha^{\prime}\right.$-dihexadecanoin (G2, Mw $\left.=568.93 \mathrm{~g} \mathrm{~mol}^{-1}\right)$; $\alpha, \alpha^{\prime}$-dioctadecanoin ( $\mathrm{G} 3, \mathrm{Mw}=625.02 \mathrm{~g} \mathrm{~mol}^{-1}$ ); tritridecanoin ( $\mathrm{G} 4, \mathrm{Mw}=681.08 \mathrm{~g} \mathrm{~mol}^{-1}$ ); and trihexadecanoin (G5, $\left.\left.\mathrm{Mw}=807.32 \mathrm{~g} \mathrm{~mol}^{-1}\right)\right]$ obtained with the DIAMS method.

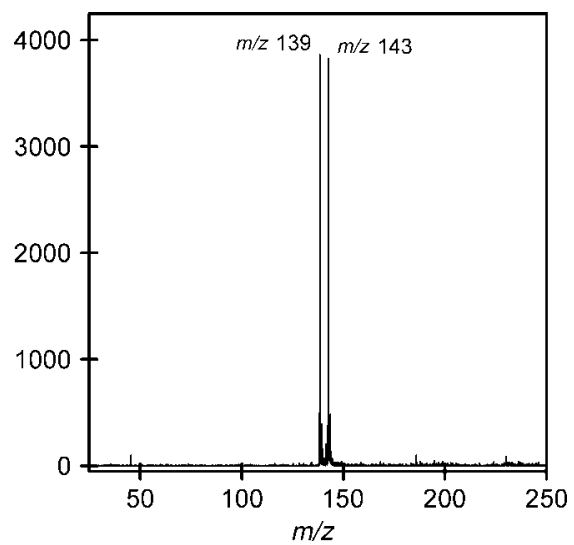

Figure 7. DIAMS mass spectrum of a mixture of salicylic acid and the corresponding $d_{6}$ isomer showing the $[\mathrm{M}+\mathrm{H}]^{+}$ions of each standard. Note that $8 \mathrm{nmol}$ of each analyte are directly deposited onto the surface.

mass spectra obtained from different solutions of diluted salicylic acid (Fig. 8).

\section{CONCLUSION}

We have demonstrated in this article that the DIAMS method is an analytical tool as statistically repeatable and reproducible as the MALDI and TGFA-LDI techniques. DIAMS can be considered as a new matrix-free LDI method using organic surface because the analyte is spotted directly onto a self-assembled monolayer. The particularity of the DIAMS concept is that the surface properties could be adapted to the nature of analyte submitted to the study by adjusting the lipophilic/hydrophilic balance. DIAMS is also a suitable method for the high throughput analyses of low molecular weights, because the analyte does not need to be mixed with the matrix to produce an adequate signal in very soft conditions (low laser energy, low volume, and low concentration). Henceforth, future directions can be undertaken: first, to understand the desorption/ionization process for DIAMS by correlating the nature, the structure 


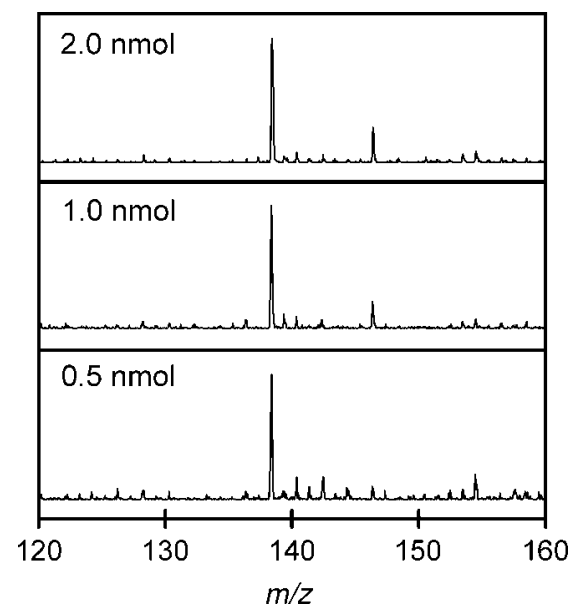

Figure 8. Relative detection limit of a mixture of salicylic acid $\left(\mathrm{HO}-\mathrm{C}_{6} \mathrm{H}_{4}-\mathrm{CO}_{2} \mathrm{H}\right)$ obtained with the DIAMS method. The values $2.0,1.0$, and $0.5 \mathrm{nmol}$ correspond to the amount of salicylic acid directly deposited onto the DIAMS plates.

and the organization of the monolayer with the results obtained in MS (nature of the observed ions, sensitivity and specificity of the detection) and second, to improve this method in several areas so it could be used in a wide range of applications.

\section{Acknowledgements}

We gratefully acknowledge support of this research by the Centre National de la Recherche Scientifique (CNRS - France), the 'Agence Nationale de la Recherche' (ANR - France), and the 'Région des Pays de la Loire' (France). The authors thank Dr N. Gallego-Planas for his critical reading of manuscript.

\section{REFERENCES}

1. Cohen LH, Gusev AI. Small molecule analysis by MALDI mass spectrometry. Analytical and Bioanalytical Chemistry 2002; 373: 571.

2. Wahl MC, Klim HS, Wood TD, Guan S, Marshall AG. Thin gold film-assisted laser desorption/ionization fourier transform ion cyclotron resonance mass spectrometry of biomolecules. Analytical Chemistry 1993; 65: 3669.

3. Wei J, Buriak JM, Siuzdak G. Desorption-ionization mass spectrometry on porous silicon. Nature 1999; 399: 243.

4. Go EP, Prenni JE, Wei J, Jones A, Hall SC, Witkowska HE, Shen Z, Siuzdak G. Desorption/ionization on silicon time-offlight/time-of-flight mass spectrometry. Analytical Chemistry 2003; 75: 2504.

5. Stewart MP, Buriak JM. Chemical and biological applications of porous silicon technology. Advanced Materials 2000; 12: 859.

6. Sunner J, Dratz E, Chen YC. Graphite surface-assisted laser desorption/ionization time-of-flight mass spectrometry of peptides and proteins from liquid solutions. Analytical Chemistry 1995; 67: 4335.

7. Peterson DS. Matrix-free methods for laser desorption/ionization mass spectrometry. Mass Spectrometry Reviews 2007; 26: 19.

8. Hutchens TW, Yip T-T. New desorption strategies for the mass spectrometric analysis of macromolecules. Rapid Communications in Mass Spectrometry 1993; 7: 576.

9. Kitagawa N, Lin S, Weinberger S. Surface enhanced neat desorption (SEND): a new mass spectrometry platform for protein identification. Proceedings of the 50th ASMS Conference on Mass Spectrometry and Allied Topics, Orlando, Florida 2002; 153.
10. Afonso C, Budimir N, Fournier F, Tabet JC. Activated Surfaces for laser desorption mass spectrometry: application for peptide and protein analysis. Current Pharmaceutical Design 2005; 11: 2559.

11. Sanguinet L, Alévêque O, Blanchard P, Dias M, Levillain E, Rondeau D. Desorption/ionization on self-assembled monolayer surface (DIAMS). Journal of Mass Spectrometry 2006; 41: 830.

12. Love JC, Estroff LA, Kriebel JK, Nuzzo RG, Whitesides GM. Selfassembled monolayers of thiolates on metals as a form of nanotechnology. Chemical Reviews 2005; 105: 1103.

13. Neudeck A, Audebert P, Guyard L, Dunsch L, Guiriec P, Hapiot $\mathrm{P}$. $\pi$-Dimer from bithiophene radical cations. Investigation of equilibrium constants as a function of substituent size and supporting electrolyte using fast conversion electrochemical cells. Acta Chemica Scandinavica 1999; 53: 867.

14. Trevor JL, Hanley L, Lykke KR. Laser desorption/vacuum ultraviolet photoionization of alkanethiolate self-assembled monolayers. Rapid Communications in Mass Spectrometry 1997; 11: 587.

15. Gong W, Elitzin VI, Janardhanam S, Wilkins CL, Fritsch I. Effect of laser fluence on laser desorption mass spectra of organothiol self-assembled monolayers on gold. Journal of the American Chemical Society 2001; 123: 769.

16. Asbury GR, Al-Saad K, Siems WF, Hannan RM, Hill HH Jr. Analysis of triacylglycerols and whole oils by matrix-assisted laser desorption/ionization time of flight mass spectrometry. Journal of the American Society for Mass Spectrometry 1999; 10: 983.

17. Ayorinde FO. Determination of the molecular distribution of triacylglycerol oils using matrix-assisted laser desorption/ionization time-of-flight mass spectrometry. Lipid Technology 2000; 12: 41.

18. Ishida $Y$, Nakanishi $O$, Hirao S, Tsuge $S$, Urabe J, Sekino T, Nakanishi M, Kimoto T, Ohtani H. Direct analysis of lipids in single zooplankter individuals by matrix-assisted laser desorption/ionization mass spectrometry. Analytical Chemistry 2003; 75: 4514.

19. Guyon F, Absalon Ch, Eloy A, Salagoity MH, Esclapez M, Medina B. Comparative study of matrix-assisted laser desorption/ionization and gas chromatography for quantitative determination of cocoa butter and cocoa butter equivalent triacylglycerol composition. Rapid Communications in Mass Spectrometry 2003; 17: 2317.

20. Krist S, Stuebiger G, Unterweger H, Bandion F, Buchbauer G. Analysis of volatile compounds and triglycerides of seed oils extracted from different poppy varieties (Papaver somniferum L.). Journal of Agricultural and Food Chemistry 2005; 53: 8310.

21. Okuno S, Wada Y, Arakawa R. Quantitative analysis of polypropyleneglycol mixtures by desorption/ionization on porous silicon mass spectrometry. International Journal of Mass Spectrometry 2005; 241: 43.

22. Cohen L, Go EP, Siuzdak G. In MALDI MS, A Practical Guide to Instrumentation, Methods and Applications. Hillenkamp F, Katalinic JP (eds). Wiley-VCH Verlag GmbH \& Co. KGaA: Weinheim (Germany), 2007; 299.

23. Hatsis P, Brombacher S, Corr J, Kovarik P, Volmer DA. Quantitative analysis of small pharmaceutical drugs using a high repetition rate laser matrix-assisted laser/desorption ionization source. Rapid Communications in Mass Spectrometry 2003; 17: 2303.

24. Wall DB, Finch JW, Cohen SA. Quantification of codeine by desorption/ionization on silicon time-of-flight mass spectrometry and comparisons with liquid chromatography/mass spectrometry. Rapid Communications in Mass Spectrometry 2004; 18: 1403.

25. Lyklema J, Van Olphen H. Terminology and symbols in colloid and surface chemistry. Part 1.13. Definitions, terminology and symbols for rheological properties. Pure and Applied Chemistry 1979; 51: 1213.

26. Okuno S, Wada Y. Measurement of serum salicylate levels by solid-phase extraction and desorption/ionization on silicon mass spectrometry. Journal of Mass Spectrometry 2005; 40: 1000. 